\title{
Modulation of the Occurrence of Heatwaves over the Euro-Mediterranean Region by the Intensity of the Atlantic Multidecadal Variability $\mathscr{O}$
}

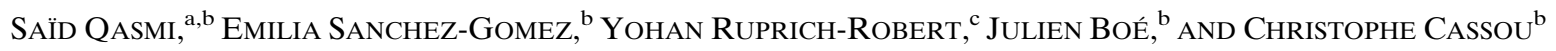 \\ ${ }^{a}$ CNRM, Université de Toulouse, Météo-France, CNRS, Toulouse, France \\ ${ }^{\mathrm{b}}$ CECI, Université de Toulouse, CNRS, Cerfacs, Toulouse, France \\ ${ }^{\mathrm{c}}$ Barcelona Supercomputing Center, Barcelona, Spain
}

(Manuscript received 23 December 2019, in final form 29 October 2020)

\begin{abstract}
The influence of the Atlantic multidecadal variability (AMV) and its amplitude on the Euro-Mediterranean summer climate is studied in two climate models, namely CNRM-CM5 and EC-Earth3P. Large ensembles of idealized experiments have been conducted in which North Atlantic sea surface temperatures are relaxed toward different amplitudes of the observed AMV anomalies. In agreement with observations, during a positive phase of the AMV both models simulate an increase (decrease) in temperature of $0.2^{\circ}-0.8^{\circ} \mathrm{C}$ and a decrease (increase) in precipitation over the Mediterranean basin of 0.1-0.2 $\mathrm{mm}^{-1 a y}{ }^{-1}$ (northern half of Europe) compared to a negative phase. Heatwave durations over the Mediterranean land regions are $40 \%$ (up to $85 \%$ over the eastern regions) longer for a moderate amplitude of the AMV. Lower and higher amplitudes lead to longer durations of $\sim 30 \%$ and $\sim 100 \%$, respectively. A comparison with observed heatwaves indicates that the AMV can considerably modulate the current anthropogenically forced response on heatwaves durations depending on the area and on the AMV amplitude. The related anticyclonic anomalies over the Mediterranean basin are associated with drier soils and a reduction of cloud cover, which concomitantly induce a decrease (increase) of the latent (sensible) heat flux, and an enhancement of the downward radiative fluxes over lands. It is found that both tropical and extratropical forcings from the AMV are needed to trigger mechanisms, which modulate the atmospheric circulation over the Euro-Atlantic region. The amplitude of the local climate response over the Mediterranean basin evolves linearly with the amplitude of the AMV. However, the strength of this relationship differs between the models, and depends on their intrinsic biases.
\end{abstract}

KEYWORDS: Europe; North Atlantic Ocean; Extreme events; Climate variability; Multidecadal variability; North Atlantic Oscillation

\section{Introduction}

Heatwaves over Europe are associated with major damage in many societal areas through increased mortality (Robine et al. 2008; Guo et al. 2017), decreased crop production (Ciais et al. 2005; Loboda et al. 2017), and increased droughts (Zampieri et al. 2009). Anticipating such extreme weather events has the potential to limit their harmful impacts.

Heatwaves (HW) are primarily driven by internal atmospheric variability (Dole et al. 2011), limiting their predictability on seasonal time scales and even more on decadal time scales (Hanlon et al. 2013). Yet, HW properties, like their duration, can be modulated by boundary conditions of the climate system, such as anthropogenic forcings (Hansen et al. 2012), but also by several of its components, including the surface via soil moisture (Alexander 2011) and the ocean through sea surface temperature (SST) (Alexander et al. 2009; Ruprich-Robert et al. 2018). At decadal time scales, oceanic modes of variability such as the Atlantic multidecadal variability (AMV) (Knight et al. 2005) seem to modulate the HW

Supplemental information related to this paper is available at the Journals Online website: https://doi.org/10.1175/JCLI-D-190982.s1.

Corresponding author: Saïd Qasmi, qasmi@cerfacs.fr variations over the adjacent continental areas, such as the United Kingdom, where several station-based HW measurements show a decadal variability during the twentieth century (Sanderson et al. 2017).

At decadal time scales, prediction skill of state-of-the-art numerical forecasts mainly comes from anthropogenic external forcing (van Oldenborgh et al. 2012). Additional skill comes from the initialization to observations of the different components of the simulated climate system, which aims to phase numerical decadal prediction variability with the observed one. In particular, decadal predictions are skillful in predicting the North Atlantic and the AMV several years in advance thanks to the initialization process (Robson et al. 2012; Yeager et al. 2018; García-Serrano et al. 2012). Yet, mean climate predictability over the adjacent continents (beyond $\sim 1$ year) is rapidly lost (Doblas-Reyes et al. 2013). Similar results are also found for initialized predictions of climate extremes (Khodayar et al. 2015; Seager and Ting 2017; Liu et al. 2019).

Such a loss of predictability seems somehow paradoxical given the apparent links that have been documented between the AMV and summer climate over Europe both in models and observations. Sutton and Hodson (2005) show that during a positive phase of the AMV, warmer conditions are obtained over central Europe, particularly over the Mediterranean basin. Concomitantly, a decrease in precipitation is obtained over this region while an increase is observed over the northern half of Europe (Sutton and Dong 2012). Mariotti and Dell'Aquila 
(2012) also found that about $30 \%$ of decadal summer temperature anomalies over the Mediterranean basin are explained by the AMV.

Current climate models show uneven results in the simulation of the teleconnection between the AMV and summer temperature over Europe, both in historical and preindustrial control CMIP5 simulations (Qasmi et al. 2017). A large intermodel spread exists in the level of teleconnectivity, partly because of numerous uncertainties in the intrinsic properties of the AMV such as its amplitude and frequency, and in the coupling mechanisms between the ocean and the atmosphere. A key challenge for the climate research community is to overcome these deficiencies by understanding how the ocean decadal variability actually influences climate over lands and how this information can be used for valuable climate predictions.

Several mechanisms have been proposed to explain the relationship between the AMV and summer climate variability over Europe. Negative sea level pressure (SLP) anomalies are observed over the British Isles during a positive phase of the AMV (hereafter AMV+) (Sutton and Hodson 2005; Sutton and Dong 2012; Ting et al. 2014), associated with positive precipitation anomalies and the absence of a significant temperature signal over northern Europe. These negative SLP anomalies have been related to the southern lobe of the summer North Atlantic Oscillation (NAO) in its negative phase (hereafter $\mathrm{NAO}-$ ). The latter seems to be more excited during the AMV+ phase (Mariotti and Dell'Aquila 2012; Linderholm and Folland 2017), with an influence extending to the Mediterranean, as suggested by Mariotti and Dell'Aquila (2012), who found that $30 \%$ of the decadal variance of Mediterranean summer precipitations is explained by the NAO. O'Reilly et al. (2017) confirm this result by separating the dynamic and thermodynamic influences of the AMV, mentioning that temperature anomalies over Mediterranean are partly explained by the largescale atmospheric circulation in the Euro-Atlantic region. Using dedicated experiments in which North Atlantic SSTs are prescribed, Sutton and Hodson (2007) show that the SLP response to an AMV forcing is consistent with the summer NAO- phase. This is confirmed by Ruprich-Robert et al. (2017), who also find a similar response in SLP and significant precipitation and temperature anomalies over Europe using idealized AMV coupled simulations.

Impacts of the AMV over the Euro-Mediterranean region have been documented in terms of mean climate, both in observations and models, but this is not the case for extreme events. Yet, the Mediterranean basin is considered as a climate change hotspot (Giorgi 2006) for which an assessment of the risks related to climate change is important since HW are expected to be more frequent in the next decades (Meehl and Tebaldi 2004; Diffenbaugh et al. 2007).

In this context, the Decadal Climate Prediction Project (DCPP) endorsed by CMIP6 (Eyring et al. 2016), and the European H2020 PRIMAVERA project (Process-Based Climate Simulation: Advances in High-Resolution Modeling and European Climate Risk Assessment; https://www.primaverah2020.eu/) aim to improve the understanding of the processes linking the AMV and climate decadal variability. For this purpose, a coordinated experimental protocol using partial coupling experiments has been proposed. In these simulations, North Atlantic SSTs are restored toward anomalies representative of the observed AMV while the rest of the system evolves freely (Boer et al. 2016; DCPP Component C).

This paper aims to assess the influence of the AMV and its amplitude on the European climate, particularly on HW durations, by using DCPP-compliant experiments from two climate models. The experimental protocol is presented in section 2. The mean temperature and HW responses to the AMV forcing and the mechanisms of teleconnection between the AMV and European HW, as well as their sensitivity to the amplitude of the AMV, are detailed in section 3. We discuss our results and conclude in section 4 .

\section{Methods and data}

\section{a. Presentation of the global climate models}

Two different global climate models are used in this study: EC-Earth3P and CNRM-CM5. The detailed features of these models can be found in Haarsma et al. (2020) and Voldoire et al. (2013), respectively. The oceanic model of EC-Earth3P is NEMO version 3.6 (Nucleus for European Modeling of the Ocean; Madec 2008); it has 75 vertical levels and a so-called ORCA1 configuration with a $1^{\circ}$ horizontal resolution. The atmospheric component is the Integrated Forecasting System (IFS), using a Gaussian grid with 91 vertical levels and a resolution of $\mathrm{N} 128$ (i.e., an approximate resolution of $0.75^{\circ}$ ). The land surface component is the Tiled ECMWF Scheme for Surface Exchanges over Land (H-TESSEL; Balsamo et al. 2009). The oceanic component is NEMO version 3.2 with the same horizontal resolution. The atmospheric component is ARPEGE-Climat-5.2 (Action de Recherche Petite Echelle Grande Echelle; Déqué et al. 1994) with 31 vertical levels and a horizontal resolution of $1.4^{\circ}$. The land surface model ISBA (Noilhan and Planton 1989) includes three surface schemes for natural land, inland water (lakes), and sea/ocean areas.

Over Europe, both models simulate realistic summertime 2-m air temperature climatology compared to observations [see Fig. 2 of Voldoire et al. (2013) and Fig. 6 of Haarsma et al. (2020) for CNRM-CM5 and EC-Earth3P, respectively].

\section{b. Model sensitivity experiments}

The DCPP framework and the experimental protocol of the idealized AMV simulations are detailed by Boer et al. (2016) (Table $\mathrm{C} 1$ and Components $\mathrm{C} 1.2$ and $\mathrm{C} 1.3$ therein; see also Technical Note 1: https:/www.wcrp-climate.org/wgsip/documents/ Tech-Note-1.pdf). The idealized experiments are intended (i) to discover how simulated European climate responds to imposed slowly evolving SST anomalies in the Atlantic (i.e., through the AMV), which are perceived as originating in ocean heat content or heat transport convergence anomalies, and (ii) to identify pathways through which the responses are expressed throughout the ocean and atmosphere. Figure 1a shows the pattern of SST anomalies used for the SST restoring for an AMV+ phase. This is done by adding a feedback term to the nonsolar total heat flux in the surface temperature equation (Haney 1971). The restoring coefficient is fixed at $-40 \mathrm{~W} \mathrm{~m}^{-2} \mathrm{~K}^{-1}$, which is equivalent to a 2-month damping 

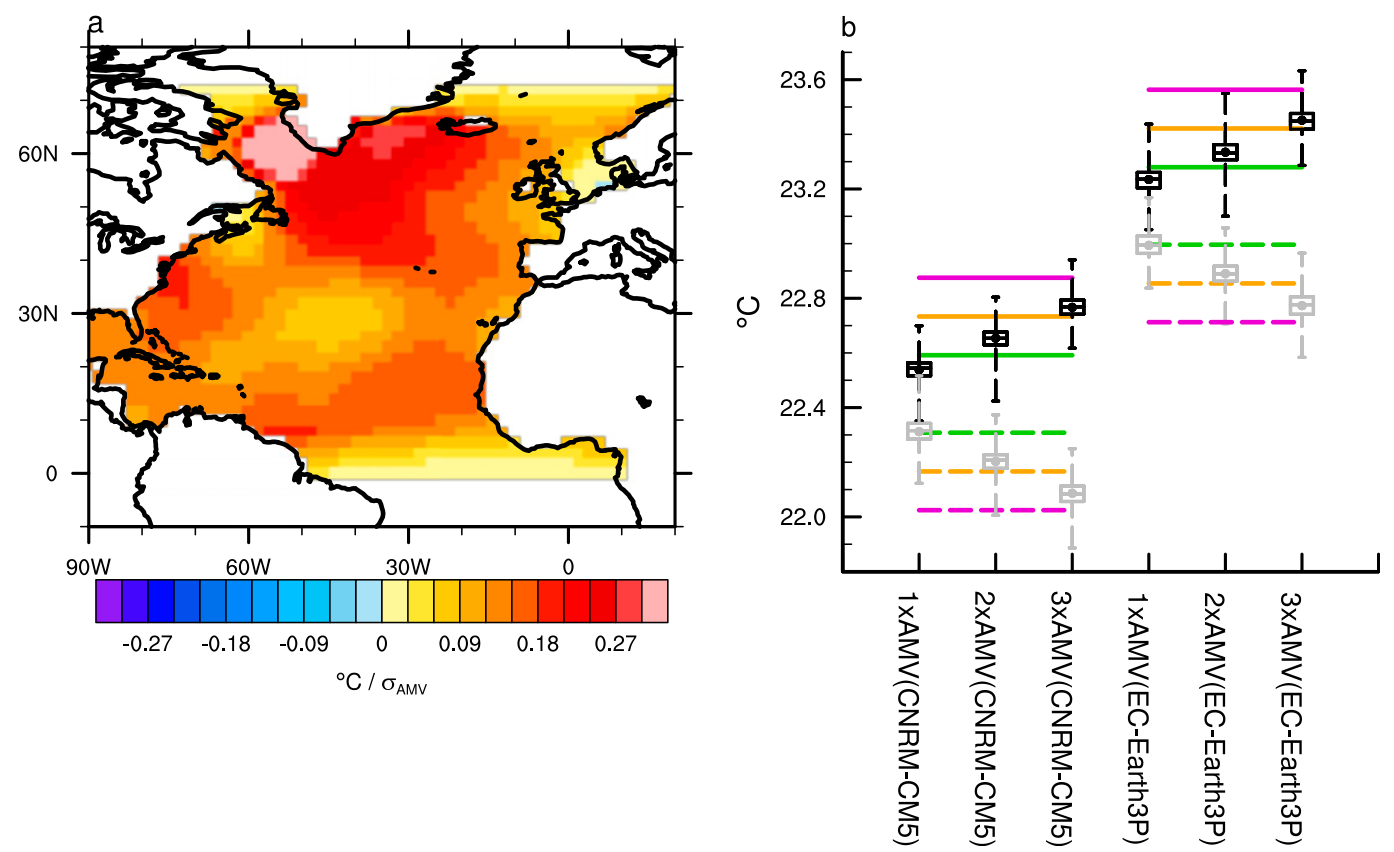

FIG. 1. (a) Anomalous SST pattern used for restoring and taken from input4MIPs archive $\left[{ }^{\circ} \mathrm{C} \sigma(\mathrm{AMV})^{-1}\right.$; shading interval is every $0.03^{\circ} \mathrm{C}$. (b) Simulated summer (JJA) SST averaged over the North Atlantic restored sector for AMV + (black) and AMV - (gray) experiments for CNRM-CM5 and EC-Earth3P. Each boxplot stands for the distribution obtained from 250 years for each ensemble ( 25 members $\times 10$ years). The top (bottom) of the box represents the first (last) tercile of the distribution and the upper (lower) whisker represents the first (ninth) decile. Dots and inside lines indicate the mean and the median of the distribution, respectively. The green, orange, and magenta horizontal lines show the SST targets for each model for the 1xAMV, 2xAMV, and 3xAMV ensembles corresponding to one, two, and three standard deviations of the observed AMV index, respectively. Solid and dashed lines, respectively, indicate AMV+ and AMV- experiments.

for a 50-m-deep mixed layer. To prevent a potential oceanic circulation drift introduced by the imposed SST anomalies, a restoring of sea surface salinity (SSS) through a freshwater flux correction is applied in EC-Earth3P to conserve the North Atlantic surface density to a neutral state (see DCPP-C Technical Note 2: https:// www.wcrp-climate.org/wgsip/documents/Tech-Note-2.pdf). The salinity drift in the CNRM-CM5 experiments is negligible and does not require an adjustment.

An AMV + and an AMV - ensemble of 40 (25) members of 10 years are computed for CNRM-CM5 (EC-Earth3P). The two ensembles differ only in the sign of the targeted SST anomalies. For an AMV+ phase, SST anomalies from Fig. 1a are superimposed on the model's own climatology to obtain the SST pattern toward which modeled SSTs are restored. The initial conditions for CNRM-CM5 (EC-Earth3P) for all the components are arbitrarily selected every 5 (6) years within a 125-yr (250-yr) control simulation conducted with CNRMCM5 (EC-Earth3P), in which radiative forcings are constant during integration, and are fixed to the 1985 (1950) estimated values. The control simulations are detailed by Oudar et al. (2017) and Haarsma et al. (2020) for CNRM-CM5 and ECEarth3P, respectively. To assess the sensitivity of the atmospheric response to the amplitude of the AMV, two additional sets of ensembles are computed for each model by multiplying the amplitude of the targeted SST anomalies by 2 and 3 (to our knowledge, only two modeling groups have conducted these additional experiments). The two additional ensembles are termed 2xAMV and 3xAMV, respectively, and the reference ensemble is referred to as $1 \mathrm{xAMV}$.

Since SSTs are not imposed but relaxed in our experiments, the amplitudes of the ensemble mean anomalies of the resulting SSTs after the restoring in CNRM-CM5 are always lower than the targeted SST for all amplitudes and both phases of the AMV, with an ensemble spread of about $0.4^{\circ} \mathrm{C}$ (Fig. 1b). Compared to CNRM-CM5, EC-Earth3P simulates a warmer North Atlantic SST mean state of $\sim 0.8^{\circ} \mathrm{C}$, explaining the warmer SST targets for both AMV + and AMV-. Despite these discrepancies, the ensemble mean differences between $\mathrm{AMV}+$ and AMV - are nearly identical between the two models for each amplitude of AMV, indicating that the imposed anomalies are the same for both models (the ensemble mean SST differences over the North Atlantic are $0.23^{\circ}, 0.45^{\circ}$, and $0.68^{\circ} \mathrm{C}$ for $1 \mathrm{xAMV}, 2 \mathrm{xAMV}$, and $3 \mathrm{xAMV}$, respectively).

The DCPP-C experimental protocol is based on a common reference to compare the responses from different climate models. The reference, which is an estimation of the observed AMV pattern, has the clear interest of estimating in the most robust way mechanisms of teleconnection between the AMV and its remote impacts. The inherent consequence associated with this choice is that the observed pattern used for restoring and may not be necessarily consistent with the AMV intrinsically simulated by the model. This might generate a response 
that is not physically coherent with the model's dynamics. We test this potential caveat by using additional ensemble experiments replicating the $1 \mathrm{xAMV}$ ensemble, but using the intrinsic AMV pattern of CNRM-CM5 estimated from the 850yr-long preindustrial control experiment (see Fig. 14a in Ruprich-Robert and Cassou 2015). This ensemble is referred as $1 \mathrm{xAMV}_{\mathrm{M}}$. The AMV-intrinsic patterns from CNRM-CM5 and EC-Earth3P are similar to the observed AMV pattern (with a spatial correlation of 0.5 for both models), except over the tropical branch where the amplitude of the SST anomalies is slightly weaker (see Fig. S1 in the online supplemental material). In CNRM-CM5 we found that the forced AMV climate response over Europe is virtually indistinguishable between the 1xAMV reference ensemble and a sensitivity ensemble we conducted using the model AMV SST anomalies (Fig. S2). Although we were not able to conduct the same experiments for EC-Earth3P, the resemblance between the two models of (i) their AMV patterns and (ii) their responses over the continent (Fig. 2) suggests that both models produce a physically coherent response to $1 \mathrm{xAMV}$ forcing, whether the intrinsic or the observed 1xAMV pattern is used in the sensitivity experiments, increasing our confidence in the adequacy of the experimental setup.

To assess the respective contributions of the tropical and extratropical parts of the AMV, additional twin ensemble experiments also proposed in DCPP-C, where the AMV full pattern is split into tropical and extratropical anomalies, have been conducted with CNRM-CM5 for the 1xAMV case (regions are defined following the DCPP-C Technical Note 1: https://www.wcrp-climate.org/wgsip/documents/Tech-Note1.pdf). These experiments are respectively named $1 \times \mathrm{AMV}_{\mathrm{T}}$ and $1 \mathrm{xAMV} \mathrm{E}_{\mathrm{E}}$.

The AMV-forced anomalies (also named response to the AMV) are defined as the ensemble mean differences between the AMV + and AMV - phases. For readability reasons, only the responses for 2xAMV experiments are shown in the main manuscript, while the responses for 1xAMV and 3xAMV are shown in the supplemental material.

\section{c. Definition of heatwaves and heatwave durations}

The definition of a HW following Ruprich-Robert et al. (2018) and Lau and Nath (2012) is adopted in this paper. For a given amplitude of the AMV, and for each member of the $\mathrm{AMV}+$ and AMV - ensemble, a HW event is defined as a group of days that satisfy three criteria: (i) Tx must exceed T90 for at least three consecutive days, (ii) Tx averaged over the entire event must exceed T90, and (iii) Tx for each day of the event must exceed the T75, where Tx is the daily maximum 2-m air temperature, and T90 (T75) corresponds to the 90th (75th) percentile of the Tx distribution built from the all the members of the AMV+ and AMV- experiments during the JuneAugust (JJA) period. Note that the thresholds have also been calculated using the control experiment regardless of the AMV phase. We found that they do not clearly differ from the ones obtained from the AMV ensembles (not shown). In this study, we focus on the impact of the AMV-forced anomalies on the mean duration of all HW events (in days) detected during an $\mathrm{AMV}+$ phase relative to $\mathrm{AMV}-$. We call the $\mathrm{HW}$ response the ensemble mean difference of the HW durations between $\mathrm{AMV}+$ and $\mathrm{AMV}-$.

\section{d. Observational composites}

We compare the responses from the different AMV experiments to observations. An estimate of the observed AMV index (also used to compute the DCPP-C AMV pattern) is defined over the 1901-2013 period, following Ting et al. (2009) and using SST data from ERSSTv4 (Huang et al. 2015). We compute anomaly differences between positive and negative phases of the AMV index for 2-m temperature (T2m), precipitation, and geopotential at $500 \mathrm{hPa}$ (Z500) using datasets from CRUTS3.2 (Harris et al. 2020), GPCC (Schneider et al. 2018), and NOAA 20CR V3 (Slivinski et al. 2019), respectively. Before computing the AMV composites, the procedure detailed by Ting et al. (2009) is also used to retrieve the response from the external forcings for each variable. This technique has been shown to provide one the least biased estimates of the observed teleconnection between the AMV and the European summer temperature (Qasmi et al. 2017).

Observed HW durations are computed over the 1981-2011 period, which includes the most recent negative (1980-95) and positive (1996-2011) phases of the AMV, using daily maximum temperature data from ERA-Interim reanalysis (Dee et al. 2011). Note that unlike the AMV simulations, the observed thresholds are only computed over the 1980-95 period (i.e., during a negative AMV phase). An estimate of the combined responses to (i) a phase shift of the AMV and to (ii) anthropogenic forcings in observed HW durations is thus defined as the HW durations difference between the 1996-2011 and 198095 periods. Comparing this estimate to the HW response from AMV experiments allows to assess the modulation of the anthropogenic trend by a phase shift of the AMV (see section 3b).

\section{Results}

\section{a. Impact of the AMV on the European summer climate}

Consistent with previous studies based on models (RuprichRobert et al. 2017) and observations (O'Reilly et al. 2017), both models simulate in 2xAMV a near-surface warming over the Mediterranean basin and northern Scandinavia in JJA, with a $\mathrm{T} 2 \mathrm{~m}$ response of $\sim 0.5^{\circ} \mathrm{C}$ (Figs. 2a,b). This warming extends to the British Isles, northern France, and central Europe in EC-Earth3P. Conversely, no signal is detectable over these regions in CNRM-CM5; a slight cooling is even obtained over the Baltic region in the latter. This difference between the two models can be explained by discrepancies between the AMV-forced responses through the atmospheric circulation and/or in the thermodynamically based processes (detailed in section 3).

A dipole of precipitation anomalies is obtained over Europe in both models, with negative (positive) anomalies south (north) of $45^{\circ} \mathrm{N}$ of $\sim-0.15 \mathrm{~mm}^{-1 a y}{ }^{-1}$, with significant values over Scandinavia and the North Sea coasts, except for EC-Earth3P, in which, following the $\mathrm{T} 2 \mathrm{~m}$ response, drier conditions are also found over western Europe. For both precipitation and $\mathrm{T} 2 \mathrm{~m}$, continent-scale anomalies in 3xAMV have 

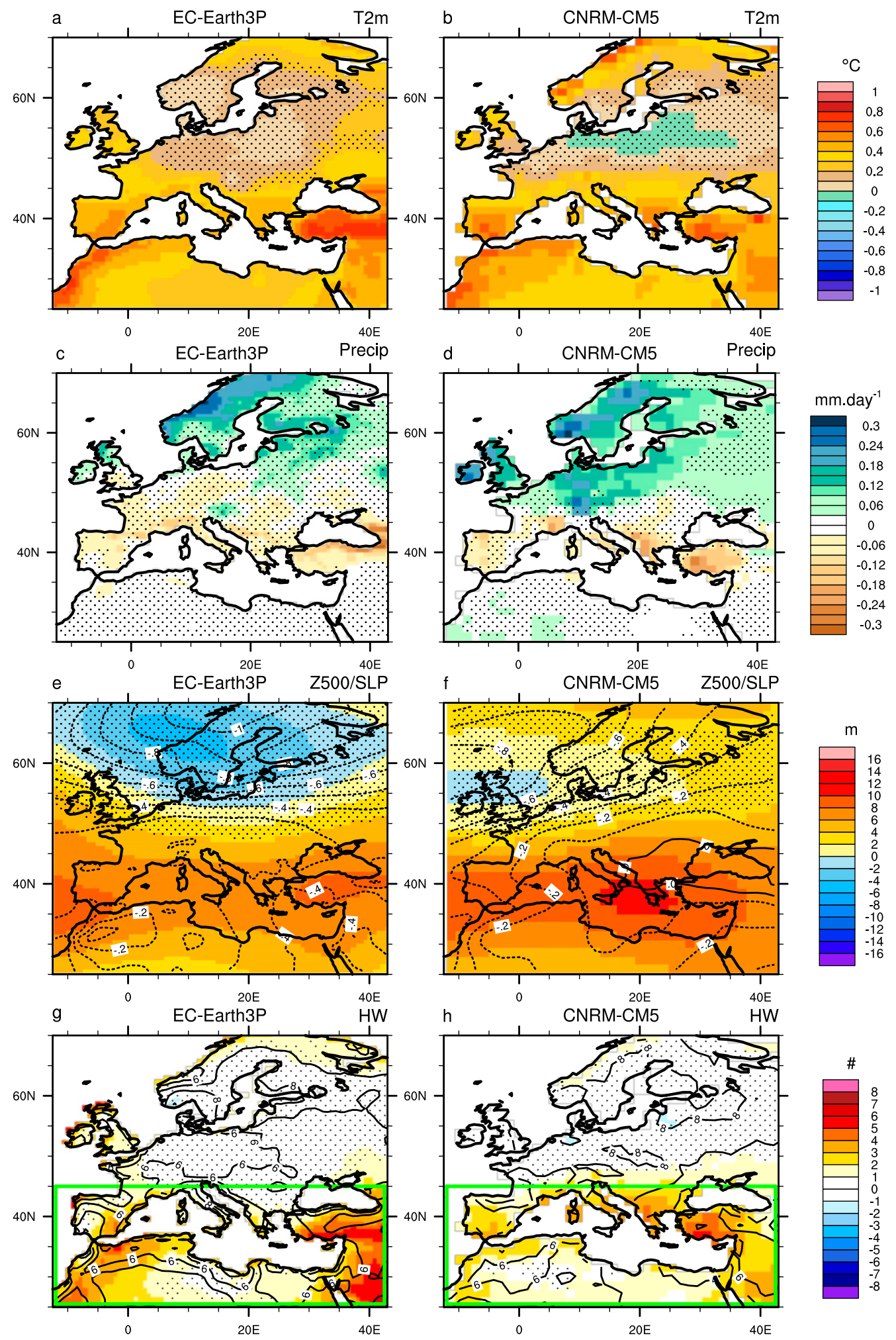

FIG. 2. AMV-forced anomalies for JJA seasonal mean for (a),(b) T2m (shading interval is $0.1^{\circ} \mathrm{C}$ ), (c),(d) precipitation (shading interval is $0.03 \mathrm{~mm} \mathrm{day}^{-1}$ ), (e), (f) SLP (contour interval is $0.1 \mathrm{hPa}$, and the thicker black contour stands for the zero line) superimposed on Z500 (shading interval is $2 \mathrm{~m}$ ), and ( $\mathrm{g}$ ),(h) HW duration overlaid by the AMV - climatology (shading interval is 1 day, and contour interval is 1 day) for (left) ECEarth3P and (right) CNRM-CM5. Stippling indicates regions that are below the $95 \%$ confidence level of statistical significance based on a two-sided Student's $t$ test. 
the same spatial structure compared to $2 \mathrm{xAMV}$, but with a greater amplitude (Figs. S3a-d; $\sim 0.8^{\circ} \mathrm{C}$ and $-0.2 \mathrm{~mm}$ day $^{-1}$ over the Mediterranean regions), while they are reduced in the 1xAMV experiments, in which the signals are hardly significant (Figs. S4a-d; $\sim 0.3^{\circ} \mathrm{C}$ and $0.1 \mathrm{~mm}$ day $^{-1}$ ). The scaling of the amplitude of the climate responses over the Mediterranean basin as a function of the AMV will be discussed in section 3d.

Consistent with previous studies (Sutton and Hodson 2007; Sutton and Dong 2012), an anomalous trough is obtained over North Sea and Scandinavia in both models in 2xAMV (black contours in Figs. 2e and 2f), coherent with the increase of precipitation over these regions. Concomitantly, an anomalous ridge at $500 \mathrm{hPa}$ of $\sim 10 \mathrm{~m}$ above negative SLP anomalies is also found over the Mediterranean region. This ridge-trough meridional dipole contributes to explain the precipitation and $\mathrm{T} 2 \mathrm{~m}$ responses on each side of $45^{\circ} \mathrm{N}$ over Europe. Noticeably, SLP and geopotential at $500 \mathrm{hPa}(\mathrm{Z} 500)$ anomalies are stronger and cover a larger area in CNRM-CM5 than in EC-Earth3P, with a minimum over the west of the United Kingdom, explaining the above-mentioned differences between the two models in terms of precipitation and temperature over western Europe. The dipolar circulation anomalies are also found in 3xAMV but with a stronger amplitude (Figs. S3e,f), whereas it is less robust in $1 \mathrm{xAMV}$, in which no significant anomalies of Z500 are detected north of $45^{\circ} \mathrm{N}$ (Figs. S4e,f).

For both models, HW are longer over the Mediterranean basin in 2xAMV (Figs. 2g,h). However, the location of the maximum anomalies differs between the two models: Anatolia, the Levant, and the Maghreb for EC-Earth3P, while the Balkans, Italy, and the Iberian Peninsula are more impacted in CNRM-CM5. For both models in $2 \mathrm{xAMV}$, the HW durations over these regions are from 3 days up to 6 days over the eastern Mediterranean longer relative to the AMV - climatology (from 6 to 7 days per summer, i.e., a relative increase by $40 \%-85 \%$; black contours in Figs. $2 \mathrm{~g}, \mathrm{~h}$ ). Consistently with the mean climate responses in $\mathrm{T} 2 \mathrm{~m}$ and precipitations, this increase is also found in 1xAMV (3xAMV), with $\sim 30 \%$ ( $100 \%)$ longer duration of the HW events.

\section{b. Comparison to observations and climate projections}

To evaluate our results, we compare the responses from the AMV experiments to the AMV composites from observations. The T2m observed composite anomalies over the Maghreb and the Levant of $\sim 0.4^{\circ} \mathrm{C}$ are similar to those obtained in the $1 \mathrm{xAMV}$ ensembles (Fig. 3a vs Figs. 2a,b), while the anomalies over the Balkan Peninsula are more similar to $2 x A M V$. For precipitations, the composite difference is not significant, making the comparison only qualitative, with a spatial structure and amplitude coherent with the simulated responses by 2xAMV (Fig. 3b vs Figs. 2c,d). Regarding the atmospheric circulation, the maximum of the Z500 anomalies is collocated with the warmest $\mathrm{T} 2 \mathrm{~m}$ observed anomalies over the Mediterranean region. Their spatial structure as well as their amplitude are remarkably similar to the Z500 anomalies obtained in 2xAMV (Figs. 3c and 2e,f).

Compared to the three AMV responses, the amplitude and spatial structure of the observed anomalies would thus correspond to a combination between 1xAMV and 2xAMV. These amplitudes are consistent with the associated standard deviations that are the most likely to be statistically sampled in observations.
That said, it is speculative to provide a firm and a quantitative conclusion since (i) given the experimental setup, SST anomalies from 1xAMV do not necessarily correspond to one standard deviation of the observed AMV (Fig. 1b), and (ii) the strength of the AMV-Europe teleconnection highly depends on the estimation of the forced signal, the temporal coverage, together with the presence of biases in the models (Qasmi et al. 2017). In addition, although the simulated responses and observed AMV composites are remarkably similar, other teleconnections may also explain European summer climate variability.

The comparison between simulated and observed HW is also complicated, because of limited maximum temperature data coverage and the difficulty of estimating the forced signal at daily time scale. This makes a quantitative estimation of the HW internal variability practically infeasible at decadal time scale. Nevertheless, as an attempt to gauge the role of the AMV in the undergoing climate change and its impacts on European HW, we compare the HW response from the AMV experiments to the HW observed composites anomalies over the 1980-2011 period, which include both responses to the external forcings and to a phase shift of the AMV (see section $2 \mathrm{~d}$ for details). Figure $3 \mathrm{~d}$ shows that the HW duration during the positive phase of the AMV over the 1996-2011 period (relative to the negative phase between 1980 and 1995) has increased by 4 days over southern Europe up to 12 days over the Maghreb and the Levant (i.e., a trend per decade of 2.5 and 7.5 days, respectively). Assuming a gradual shift between two 10-yr AMV phases, a change of 3 and $6 \mathrm{HW}$ days over these regions (see Figs. $2 \mathrm{~g}, \mathrm{~h}$ ) results in a trend per decade of 2.25 and 5.5 days. Therefore, assuming, as above, that observations fall between the 1xAMV and 2xAMV ensembles, the AMV could modulate the current anthropogenic trend by $60 \%-90 \%$ over southern Europe and by $40 \%-70 \%$ over the Maghreb and the Levant, with however a very high level of uncertainty due to the short temporal coverage of the observations.

A crude and qualitative estimation of this modulation in the near-term future climate is also done by using the CNRM-CM5 climate projections. Results show that even for a high-emission scenario, the AMV may still modulate HW variability by $\sim 30 \%$ in terms of duration over the $2021-40$ period (Fig. S5).

In the following section, we investigate the mechanisms that may explain the climate responses characterized in this section. We will focus both on processes leading to local thermodynamic changes and those causing the atmospheric circulation changes.

\section{c. Influence of the AMV-forced SST anomalies on thermodynamical processes}

The Z500 anticyclonic anomalies located over the Mediterranean region are associated with a significant decrease of total cloud cover in EC-Earth3P in 2xAMV of $\sim 10 \%$ (Fig. 4a). This decrease is less pronounced in CNRM-CM5 ( $\sim 8 \%$; see Fig. $4 \mathrm{~b})$, and restricted to the eastern part of the Mediterranean basin (a slight increase is even obtained over the western Maghreb, the Iberian Peninsula, and northern Europe). These anomalies induce changes in the surface radiation budget: anomalies up to $\sim 5 \mathrm{~W} \mathrm{~m}^{-2}$ in the sum of the downward longwave (LW) and shortwave (SW) radiation are found over regions associated with a decrease of total cloud cover 

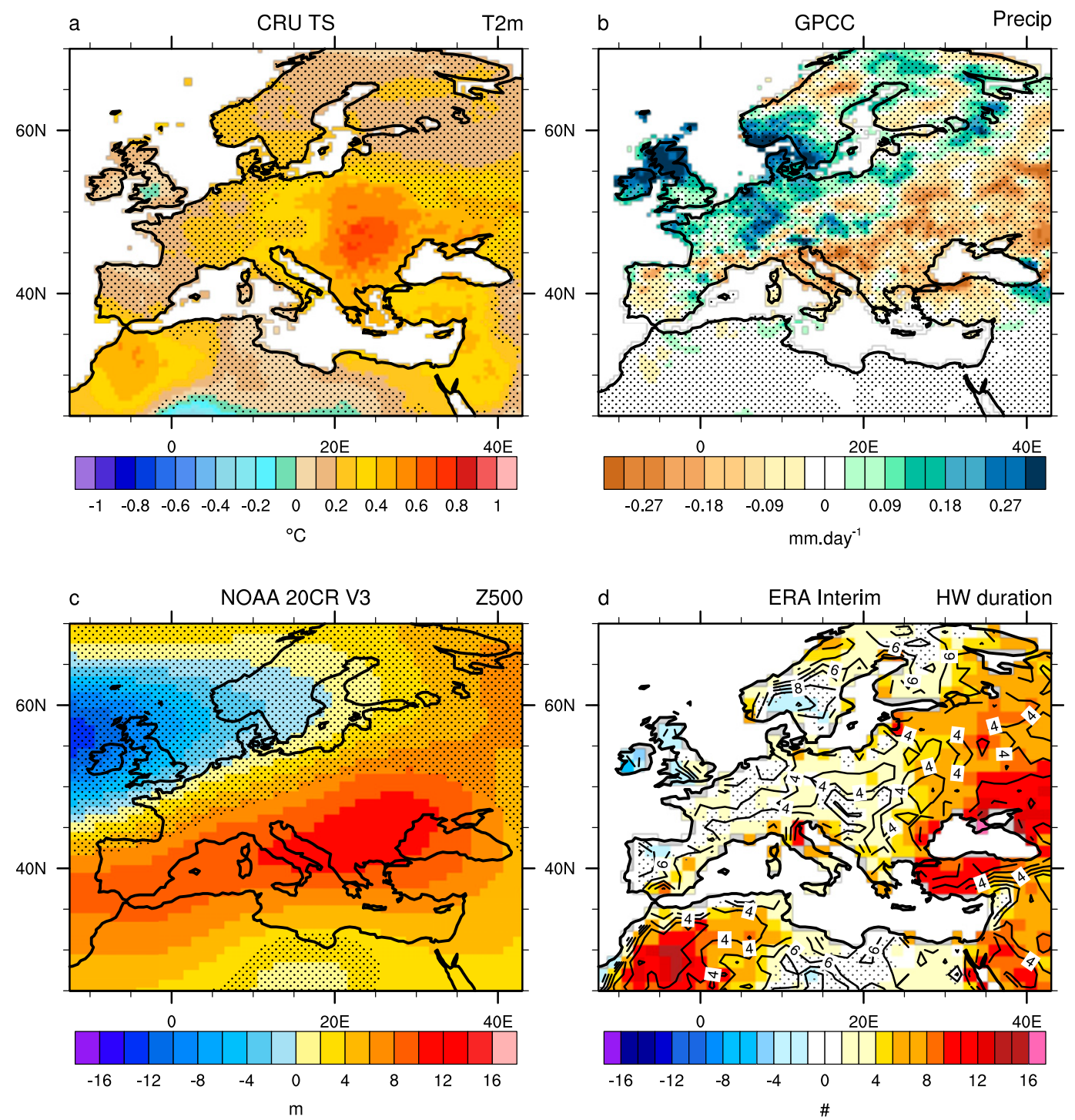

FIG. 3. JJA seasonal mean observed composite anomalies (see section $2 \mathrm{~d}$ for the detailed description of the calculations) for (a) $\mathrm{T} 2 \mathrm{~m}$ (shading interval is $0.1^{\circ} \mathrm{C}$ ), (b) precipitation (shading interval is $0.03 \mathrm{~mm} \mathrm{day}^{-1}$ ), (c) Z500 (shading interval is $2 \mathrm{~m}$ ), and (d) HW duration (shading interval is 1.3 day) overlaid by the AMV- composite (contour interval is 1 day). Note that the color scale for the HW response is different from that of Fig. 2 to display higher amplitudes.

(Figs. 4c,d), which is spatially consistent with the T2m response (Figs. 2a,b) and the increase in the HW durations (Figs. 2g,h). Note that in CNRM-CM5, positive radiation anomalies of $\sim 4 \mathrm{~W} \mathrm{~m}^{-2}$ are also obtained over northwestern African coasts and the Iberian Peninsula although cloud cover increases over these regions, suggesting the impact of other processes on the positive downward radiation. The lower troposphere warming and moistening also impact downward LW radiation, and partly explain the positive LW + SW anomalies over the Mediterranean basin. Unfortunately, LW and SW radiation fields in clear-sky conditions have not been saved to precisely assess the radiative contribution of cloud cover anomalies.

In both models, a negative latent heat flux response (i.e., a decrease in evapotranspiration of $\sim-6 \mathrm{~W} \mathrm{~m}^{-2}$ ) is obtained over the eastern Mediterranean coasts (Figs. 4e,f), where the HW duration lengthening is the largest (Figs. $2 \mathrm{~g}, \mathrm{~h}$ ). As no particular drying is obtained over these regions in the previous spring and winter (not shown), this decrease of evapotranspiration is associated with the concomitant negative precipitation response (Figs. 2c,d), therefore causing a surface heating and enhancing the probability of HW occurrence. Positive anomalies of sensible heat flux $(\mathrm{SH})$ of $\sim 6 \mathrm{~W} \mathrm{~m}^{-2}$ are obtained over the Mediterranean coasts, particularly over the eastern side of the basin, where the soil warming is directly impacted by the increase in downward SW radiation and dry conditions (Figs. $4 \mathrm{~g}, \mathrm{~h}$ ).

In addition to the direct effect of the negative cloud cover anomalies on the radiative fluxes, other processes may 

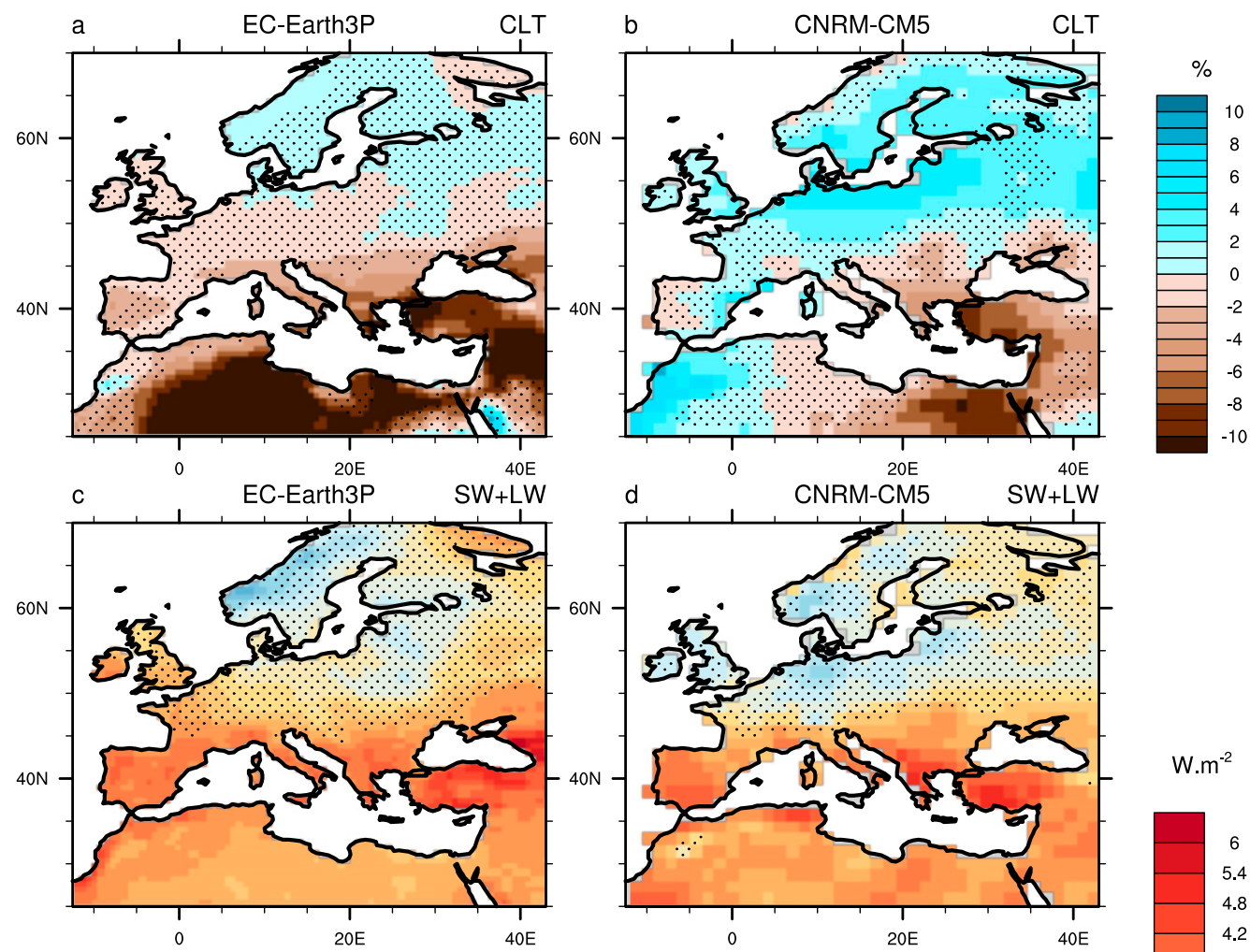

W. $\mathrm{m}^{-2}$
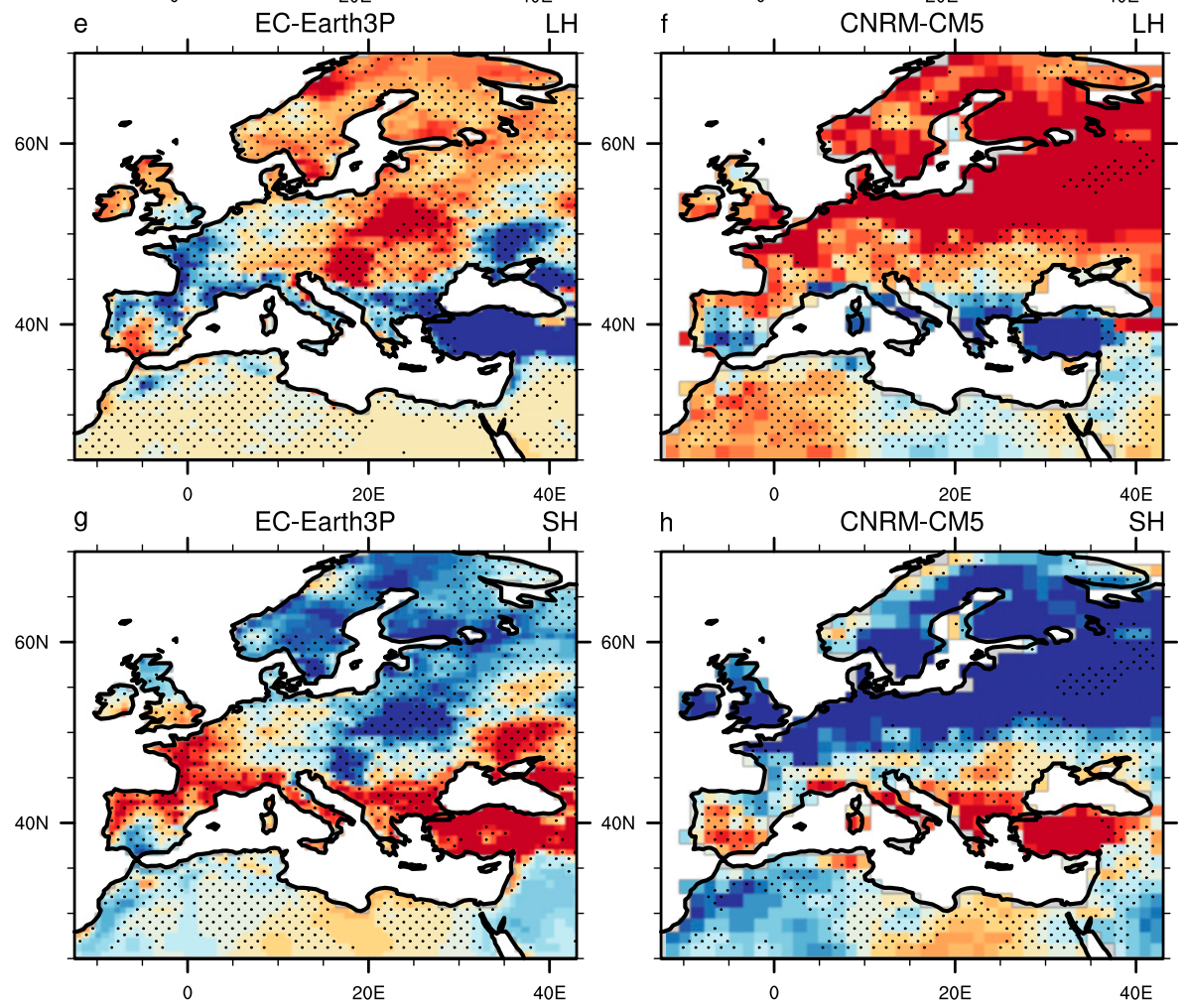

FIG. 4. AMV-forced anomalies for JJA seasonal mean for (a),(b) total cloud cover (shading interval is $1 \%$ ), (c),(d) downward LW and SW radiation at surface (shading interval is $0.6 \mathrm{~W} \mathrm{~m}^{-2}$ ), (e),(f) latent heat at the surface, and (g),(h) sensible heat for (left) EC-Earth3P and (right) CNRM-CM5. Positive values of downward LW and SW (LH and SH) represent heat transfer toward (from) the surface. Stippling indicates regions that are below the $95 \%$ confidence level of statistical significance based on two-sided Student's $t$ test. 
contribute to the T2m and HW responses, especially over the western Mediterranean and the Levant, where a response from the turbulent heat fluxes is not detectable. In CNRM-CM5, it is found that the northwestern African coasts, the Iberian Peninsula, and the Levant are under the influence of the advection by the climatological wind of positive temperatures anomalies from North Atlantic and the Mediterranean Sea, where SST anomalies are positive during an AMV+ phase, contributing to the increase obtained in the downward LW fluxes (not shown).

Coherently with the T2m and HW responses, similar responses in the radiative fluxes are found in the 3xAMV and 1xAMV experiments (Figs. S6 and S7), in which the amplitude of the anomalies are stronger and weaker, respectively.

The circulation changes associated with the thermodynamic response and with the impacts in $\mathrm{T} 2 \mathrm{~m}$ and precipitation over the Euro-Mediterranean region are discussed in the next section.

\section{d. Influence of the AMV-forced SST anomalies on the atmospheric circulation}

The Z500 response to the AMV is characterized by anticyclonic (cyclonic) anomalies centered over Greenland (northwestern Europe) and projects on the NAO pattern (Figs. 2e,f). Previous studies focusing on the observed AMV impacts have suggested several mechanisms leading to a very similar Z500 response.

Based on observational analysis, Dong et al. (2013) suggest a local influence of the AMV on the NAO: during an AMV+ phase, the weakening of the SST meridional gradient over the subpolar gyre induces a southward shift of the westerly winds and the storm tracks whose fingerprint resembles the summer NAO-. This shift leads to similar temperature and precipitation anomalies to those shown in Figs. 2c and 2d: enhanced precipitation over the United Kingdom and northwestern Europe and decreased precipitation over the Mediterranean basin (their Fig. 3). However, no significant anomalies in the summer storm tracks are detected in our idealized AMV experiments (not shown).

Several studies also suggest that the Z500 anomalies over Europe are part of a larger-scale pattern. Bladé et al. (2012) show that a negative (positive) phase of the NAO is associated with a Z500 tripolar structure, characterized by a Z500 dipole located over the eastern Atlantic and northern Europe and an anomalous ridge (trough) over the Mediterranean basin. The authors interpret this tripole as part of a circumglobal wavelike pattern of anomalies over the Northern Hemisphere. A similar response is obtained in CNRM-CM5 and EC-Earth3P, which also indicates a wavelike pattern of Z500 anomalies in 2xAMV (Z500*; Figs. 5a,b; note that Z500 zonal means have been subtracted to account for the mean dilatation of the atmosphere due to the artificial heat source introduced in the model in the experiments via the flux restoring term) with positive anomalies over the North Pacific, northeastern America, Greenland, and the Mediterranean Sea and negative anomalies over western North America and northern Europe. This wavelike pattern is robust across the three amplitudes of the AMV (Figs. S9 and $\mathrm{S} 10$ ), with a stronger (weaker) amplitude in 3xAMV (1xAMV).

Several mechanisms implying the AMV have been proposed to explain this wavelike pattern. They are based on both the tropical and extratropical AMV-forced SST anomalies.
Ghosh et al. (2017, 2019) claim that the negative Z500 anomalies over western Europe result from a linear baroclinic response triggered by a diabatic heating over the northwestern Atlantic during an AMV+ phase (Gulev et al. 2013), inducing an easterly wavelike response. Lin et al. (2016) also suggest an influence of the AMV-forced extratropical SST on the multidecadal variability of the wavelike circumglobal pattern, they found in idealized experiments that the circulation anomalies over Europe are rather of a barotropic type. A diabatic heating source (identified by the positive precipitation anomalies used as proxy) is found over south of Newfoundland in the AMV experiments for the three amplitudes (Figs. 5c,d; see also Figs. S8 and S9). The associated cyclonic SLP and Z500 anomalies collocated with the heat flux anomalies indicate a barotropic response (Fig. S10 and Figs. 5a,b), which seems to scale linearly with the AMV amplitude.

Alternative mechanisms imply a key role from tropical Atlantic in modulating the atmospheric circulation in the extratropics. Wang et al. (2012) show that the observed multidecadal changes in the circumglobal teleconnection during the last century have been partially due to the West African monsoon. The latter is known to be enhanced during an AMV + phase via the tropical Atlantic (Zhang and Delworth 2006; Martin and Thorncroft 2014), which is also the case in our experiments (Figs. 5c,d). According to Wang et al. (2012), the African monsoon, acting as a heat source and coupled with the upper-level jet stream, generates a Rossby wave response, which may modulate the atmospheric circulation over the Euro-Atlantic region. Alternatively, Gaetani et al. (2011) and Cassou et al. (2005), among others, suggest another mechanism, which is based on a direct meridional overturning circulation between the tropics and the Mediterranean basin, triggered by the enhanced West African monsoon, and/or by the tropical Atlantic warming during an AMV+ phase. To characterize the respective upward and downward motions relative to a meridional circulation response over these two regions, we assess the vertical velocity anomalies at $300 \mathrm{hPa}$ in the AMV experiments. Consistently, a strong upward (downward) branch over the tropical eastern Atlantic and Africa (the Maghreb) is obtained in EC-Earth3P (Figs. S11a-c). However, this is less clear in CNRM-CM5, in which the enhancement of the upward velocity is weaker over tropical Africa even for strong AMV-forced SST anomalies (Figs. S11d-f).

Assessing (i) the relevance of each of the above-mentioned mechanisms in each model and (ii) their sensitivity to the amplitude of the AMV requires further dedicated experiments and analyses, which are beyond the scope of this study. However, we provide here a qualitative estimation of the contribution of the tropical and extratropical part of the AMV on atmospheric circulation anomalies by using the additional twin ensemble experiments $1 \mathrm{xAMV}_{\mathrm{T}}$ and $1 \mathrm{xAMV} \mathrm{V}_{\mathrm{E}}$. Figure 6 shows that the Z500* anomalies obtained over the EuroMediterranean region in the full pattern experiments for CNRM-CM5 are not due to an exclusive SST forcing from the tropics or from the extratropics. Anticyclonic anomalies over the eastern and western sides of the Mediterranean basin obtained in 1xAMV (where the HW response is the strongest) are also found in $1 \mathrm{xAMV}_{\mathrm{T}}$ and $1 \mathrm{xAMV}_{\mathrm{E}}$ (Figs. 6a,b). However, 

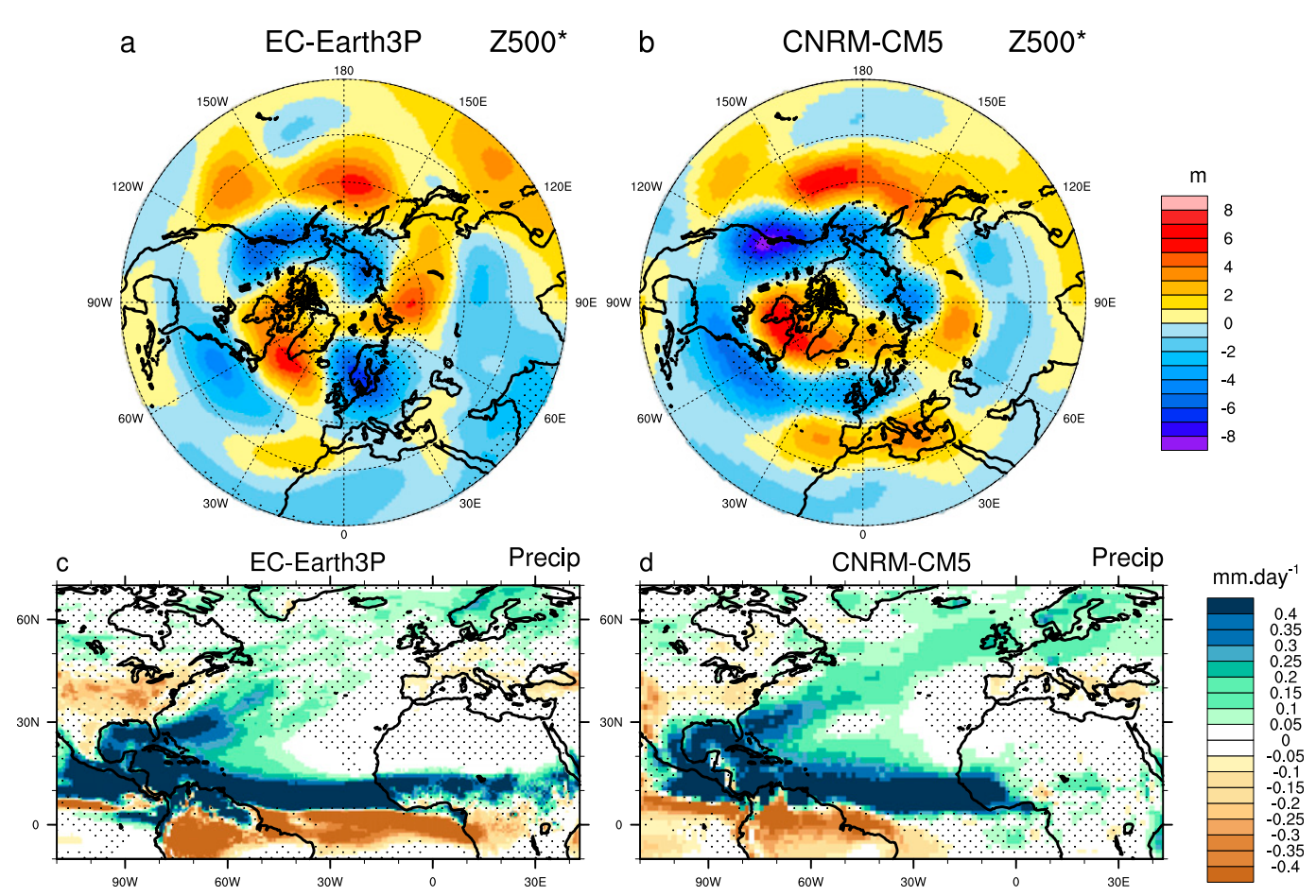

FIG. 5. AMV-forced anomalies for JJA seasonal mean for (a),(b) Z500* (shading interval is $1 \mathrm{~m}$ ) and (c),(d) precipitation (shading interval is $0.05 \mathrm{~mm} \mathrm{day}^{-1}$ ) for (left) EC-Earth3P and (right) CNRM-CM5. Note that Z500 zonal means have been retrieved to account for the mean dilatation of the atmosphere due to the artificial heat source introduced in the model in the idealized experiments via the flux restoring term. Stippling indicates regions that are below the $95 \%$ confidence level of statistical significance based on a two-sided Student's $t$ test.

these anomalies in $1 \mathrm{xAMV}_{\mathrm{T}}$ seem to be part a larger wavelike pattern from the Irminger Sea to Egypt, while they are weaker in $1 \mathrm{XAMV}_{\mathrm{E}}$. Although with slightly different spatial locations, the circumglobal response in $1 \mathrm{xAMV}$ is found in $1 \mathrm{xAMV}_{\mathrm{E}}$ but not in $1 \mathrm{xAMV}_{\mathrm{T}}$. Even if the response is hardly significant, it supports the idea of key role from the extratropical SSTs.

The additivity hypothesis of the tropical and extratropical impacts on the atmospheric circulation is tested by comparing the sum of the $1 \mathrm{xAMV} \mathrm{E}_{\mathrm{E}}$ and $1 \mathrm{xAMV}_{\mathrm{T}}$ responses to the $1 \mathrm{xAMV}$ response. Figures $6 \mathrm{c}$ and $6 \mathrm{~d}$ shows the comparison between the $\mathrm{Z} 500 *$ response in $1 \mathrm{xAMV}_{\mathrm{T}}+1 \mathrm{xAMV}_{\mathrm{T}}$ compared to $1 \mathrm{xAMV}$. The additivity assumption is not valid over the subpolar gyre and central Europe where opposite-sign responses are obtained; however, the tripolar Z500* anomalies over the Mediterranean basin in $1 \mathrm{xAMV}_{\mathrm{T}}+1 \mathrm{xAMV}_{\mathrm{T}}$, although slightly shifted, are similar to those obtained in the full pattern response. These results indicate a combined role of the tropical and the extratropical AMV-forced SST anomalies to explain the atmospheric response over the Euro-Atlantic region. This is confirmed through the climate impacts over Europe, where the HW response over the Mediterranean regions is weaker when the SST forcing is applied separately in $1 \mathrm{xAMV}_{\mathrm{E}}$ and $1 \mathrm{xAMV}_{\mathrm{T}}$ relative to the $1 \mathrm{xAMV}$ case (Fig. 7), even if, the same experiments in the 2XAMV and 3xAMV cases are needed to confirm this result.

The spatial patterns of the $\mathrm{T} 2 \mathrm{~m}, \mathrm{HW}$, and $\mathrm{Z} 500$ responses shown in Figs. 2-4 indicate a progressive reinforcement of the anomalies with the amplitude of the AMV in both models. The next section aims at quantifying the degree of linearity between the atmospheric response and the amplitude of the AMVforced SST anomalies.

\section{e. Linearity between the AMV-forced SST anomalies and the climate response over the Mediterranean basin}

The intensity of the $\mathrm{T} 2 \mathrm{~m}$ response seems to be a linear function of the amplitude of the AMV for both models (Fig. 8a). A linear relationship is also obtained for the HW response, but unlike the $\mathrm{T} 2 \mathrm{~m}$ responses, the slope is, according to a $t$ test, significantly greater for EC-Earth3P $\left(4.6\right.$ days $\left.{ }^{\circ} \mathrm{C}^{-1}\right)$ than for CNRM-CM5 (2.3 days $\left.{ }^{\circ} \mathrm{C}^{-1}\right)$. The intercept is also higher for EC-Earth3P and denotes that the climatological HW duration is higher in this model. We find a similar result for precipitation anomalies over the Mediterranean basin, which decrease linearly with the AMV amplitude (not shown). This discrepancy between the two models in the AMV/HW relationships can be due to two reasons: (i) different intrinsic model differences leading to different responses and (ii) different external forcing background states (1950 for EC-Earth3P and 1985 for CNRM-CM5). The first one could be associated with different climatologies between the two models impacting the HW response (e.g., a weaker climatological soil moisture in EC-Earth3P than in CNRM-CM5 during summer). Assessing the contribution of this feature would require further experiments, which are beyond the scope of the study.

The sensitivity of the response to the mean state background driven by external forcings is evaluated with CNRM-CM5, for 

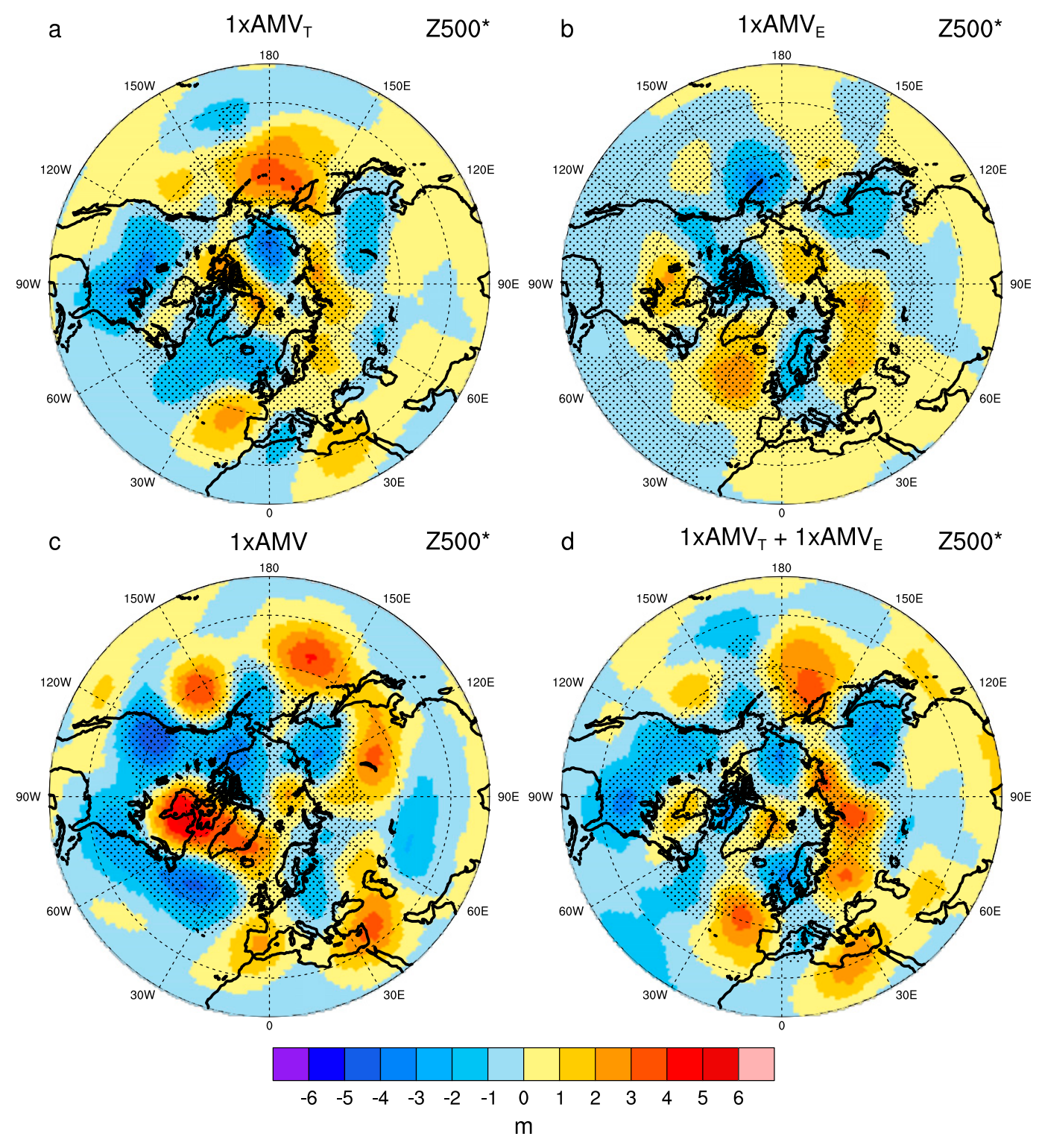

FIG. 6. AMV-forced anomalies for JJA seasonal mean for Z500* (shading interval is $1 \mathrm{~m}$ ), for CNRM-CM5 for (a) $1 \mathrm{xAMV}_{\mathrm{T}}$, (b) $1 \mathrm{xAMV}$, (c) $1 \mathrm{xAMV}$, and (d) the sum $1 \mathrm{xAMV}_{\mathrm{T}}+1 \mathrm{xAMV}$. Stippling indicates regions that are below the $95 \%$ confidence level of statistical significance based on a two-sided Student's $t$ test.

which additional simulations were performed with an $1850 \mathrm{ex}$ ternal forcing background (Qasmi et al. 2020). These simulations are similar to those used in this paper except that they are initialized from the conditions of the CMIP5 preindustrial control simulation of CNRM-CM5, in which external forcings are maintained at the 1850 level. The comparison between these two types of experiments, named CNRM-CM5(1850) and CNRMCM5(1985), shows that the mean background state has no clear influence on the AMV/T2m linear relationship (Fig. 8c): although the $\mathrm{T} 2 \mathrm{~m}$ response in the CNRM-CM5(1850) simulation is weaker with a lower intercept of $\sim 0.1^{\circ} \mathrm{C}$, the same slope of $0.8^{\circ} \mathrm{C}^{\circ} \mathrm{C}^{-1}$ is obtained for both mean background states. This indicates that there is no interaction between the external forcings and the
AMV-forced response. A similar result is obtained for the HW response, for which CNRM-CM5(1985) and CNRM-CM5(1850) are almost indistinguishable from each other, with slopes of 2.3 and 2.8 days ${ }^{\circ} \mathrm{C}^{-1}$, respectively.

A linear relationship between the SST amplitude and the local dynamical and thermodynamical responses over the Mediterranean basin is also found (Fig. S12; note that it is not noticeable in CNRMCM5, for which there is a sign compensation between the eastern and western parts of the Mediterranean basin for the $\mathrm{LH}, \mathrm{SH}$, and downward SW anomalies; see Figs. 4f,h). However, the linearity of the $\mathrm{T} 2 \mathrm{~m} / \mathrm{HW}$ response does not necessarily imply a linearity of the large-scale mechanisms leading to this response. The precise origins of the latter, discussed in section $3 \mathrm{~d}$, as well as their sensitivity 

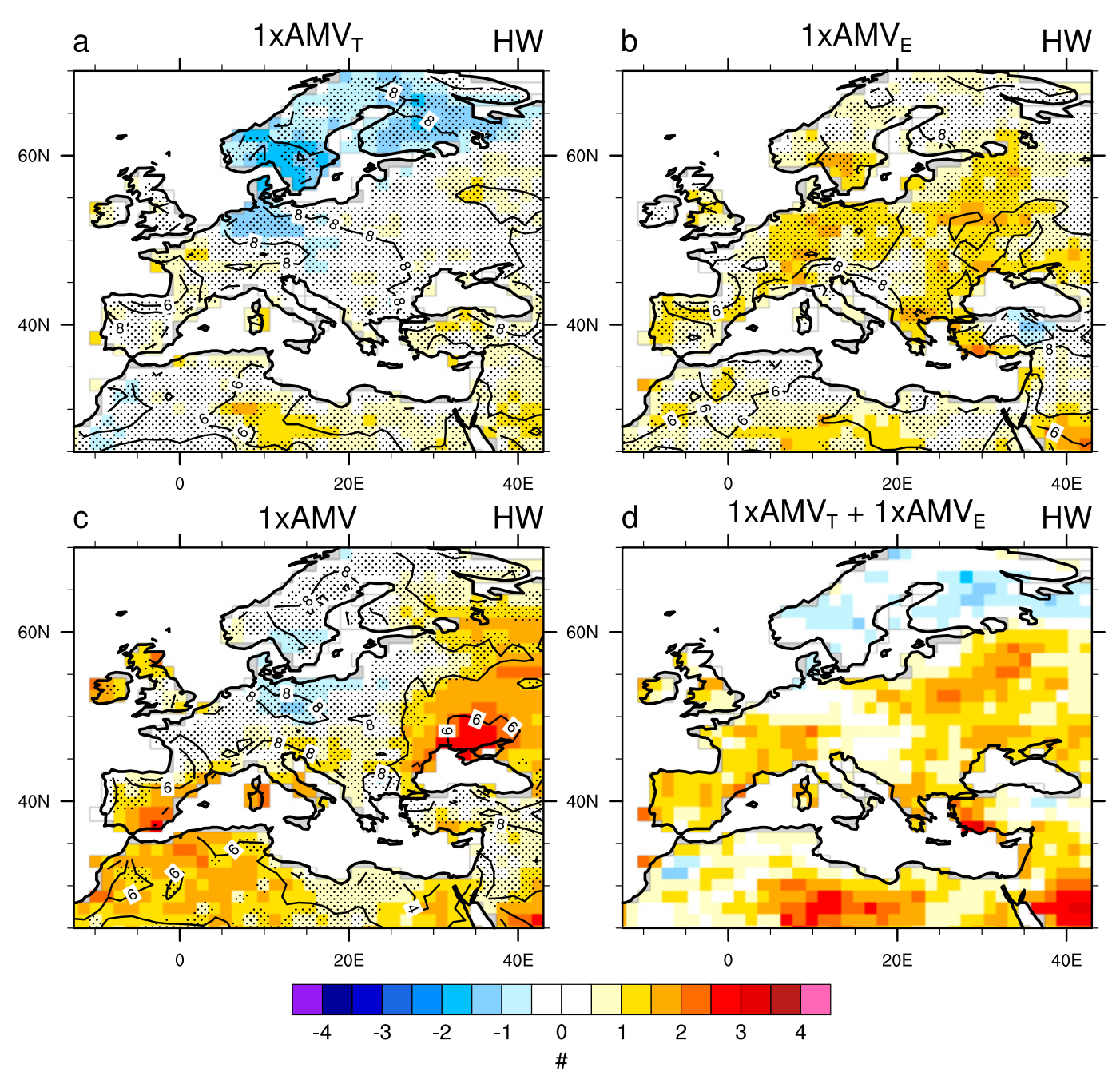

FIG. 7. As in Fig. 6, but for the HW response (shading interval is 0.5 day). Note that neither statistical significance nor the HW climatology is computed for (d), since the thresholds used to compute the HW responses in $1 \mathrm{xAMV}_{\mathrm{T}}$ are different from the ones used for $1 \mathrm{xAMV}_{\mathrm{E}}$.

to the amplitude of the AMV still remain to be clearly identified. Note also the larger spread of the T2m and HW anomalies in CNRM-CM5(1850) than in CNRM-CM5(1985). The reduction of the spread with the 1985 background may correspond to a stronger signal-to-noise ratio in the latter, which could be interpreted as the impact of the anthropogenic forcing, which tends to reduce the atmospheric noise over the Mediterranean basin (Bengtsson et al. 2006). Assuming that the level of interactions between AMV and the external forcings, which is found to be very limited in CNRMCM5, is not model dependent, the differences between CNRMCM5 and EC-Earth3P in the AMV/HW linear relationships may therefore depend on their respective intrinsic biases.

\section{Conclusions and discussion}

The impacts of the AMV on the European summer climate are studied in two climate models, EC-Earth3P and CNRMCM5, using idealized experiments in which the North Atlantic
SST is restored toward anomalies characteristic of the observed AMV. To estimate the sensitivity of the atmospheric response to the amplitude of the AMV, three ensembles of simulations are performed, corresponding to one, two, and three standard deviations of the observed AMV. Both climate models are coherent in the surface temperature and precipitation responses and show that during a positive phase of AMV an increase (decrease) in $\mathrm{T} 2 \mathrm{~m}$ and a decrease (increase) in precipitation are obtained over the Mediterranean basin (northern half of Europe). For both models and a moderate amplitude of the AMV, the HW durations over the Mediterranean regions are from 3 days up to 6 days over the eastern Mediterranean longer relative to the AMV climatology (i.e., a relative increase by $40 \%$ up to $85 \%$ ). The associated midtroposphere response is characterized by an anomalous trough (ridge) over northern Europe (the Mediterranean Sea), which is coherent with the responses in $\mathrm{T} 2 \mathrm{~m}, \mathrm{HW}$, and precipitation. These results are consistent with previous studies based on a similar experimental protocol (Ruprich-Robert et al. 2017) 

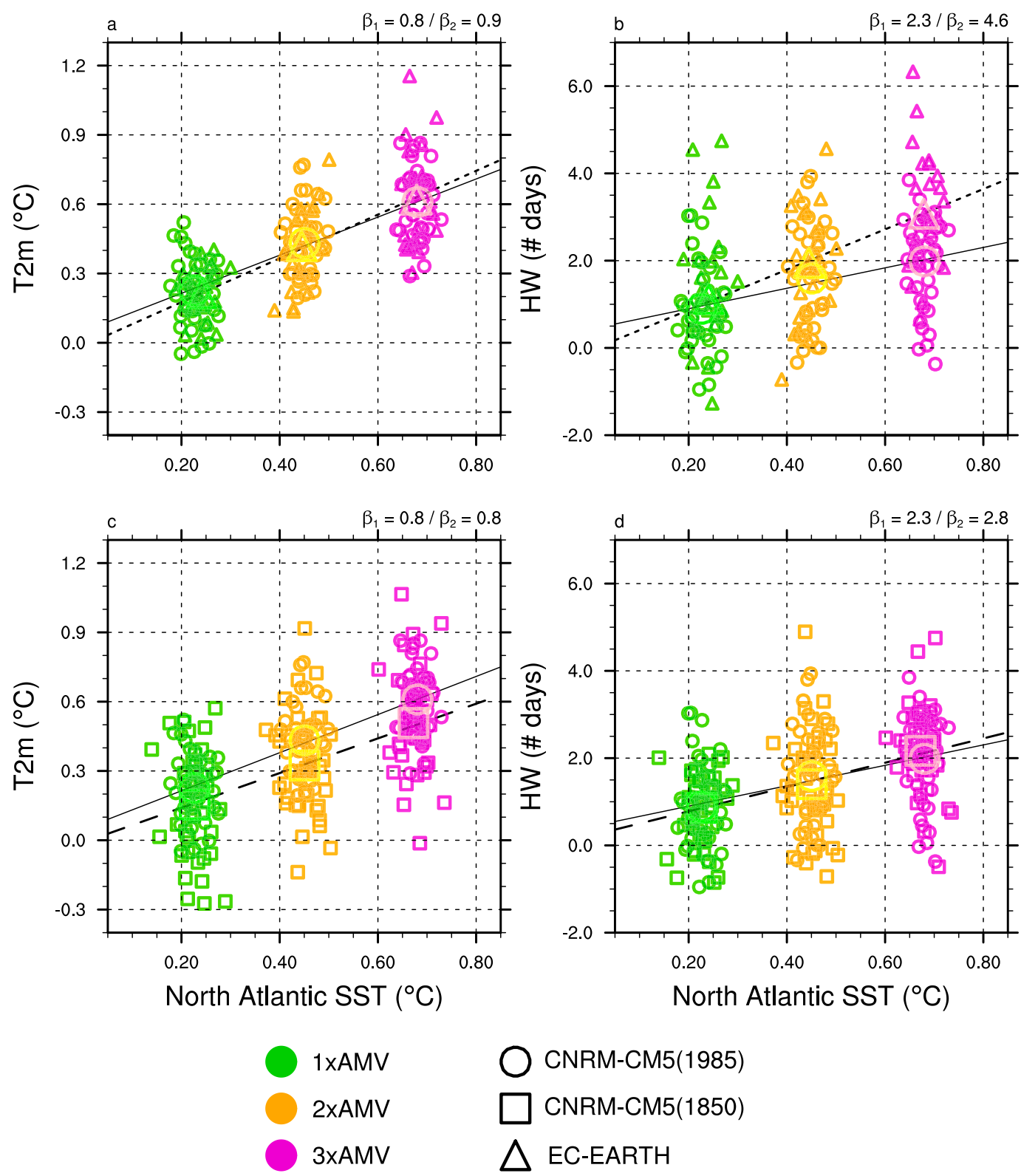

FIG. 8. Spatial average of AMV-forced anomalies for JJA seasonal mean of North Atlantic SST $\left(0^{\circ}-60^{\circ} \mathrm{N}\right)$ vs (left) T2m and (right) HW duration over the Mediterranean basin (green domain over Figs. $2 \mathrm{~g}$ and $2 \mathrm{~h}$ ) for (a),(b) CNRM-CM5(1985) and EC-Earth3P and (c),(d) CNRM-CM5(1985) and CNRM-CM5(1850) for 1xAMV (green), 2xAMV (orange), and 3xAMV (magenta). The small dots, squares, and triangles represent the 10-yr mean response of each member and the big dots, squares, and triangles indicate the ensemble mean. Solid (for dots) and dashed (for squares or triangles) lines are obtained from the linear regression between the T2 $\mathrm{m} / \mathrm{HW}$ and the SST anomalies distributions from all the experiments. The slope $\left({ }^{\circ} \mathrm{C}^{\circ} \mathrm{C}^{-1}\right.$ for $\mathrm{T} 2 \mathrm{~m}$ or number of days ${ }^{\circ} \mathrm{C}^{-1}$ for $\left.\mathrm{HW}\right)$ is given in the upper right title of each panel ( $\beta_{1}$ for the solid line, $\beta_{2}$ for the dashed line).

and observations (Sutton and Dong 2012, their Figs. 2 and 3). For an observed AMV amplitude of two standard deviations, HW event durations can rise by $40 \%$ up to $85 \%$ over several regions of the Mediterranean basin, especially over its eastern part, where both models exhibit the most robust response. The similarity between the AMV-forced simulated responses and observations suggests that the observed $\mathrm{T} 2 \mathrm{~m}$ anomalies over Europe result from a forcing by the AMV rather than being a consequence of the sole atmospheric internal variability. Model evaluation shows that the most realistic simulated AMV-forced responses of $\mathrm{T} 2 \mathrm{~m}$, precipitation, and Z500, relative to the observed composites, correspond to an intermediate amplitude of between one and two standard deviations. In the broader context of global warming, our results suggest that the AMV could modulate the current 
anthropogenically forced response on HW durations by $40 \%-$ $90 \%$ depending on the area. For a high-emission scenario, this modulation is $\sim 30 \%$ over the $2021-40$ period.

Thermodynamically driven mechanisms explain the warming obtained over the Mediterranean basin. A decrease in total cloud cover over this region during an AMV+ phase induces an increase in downward shortwave radiation, which contributes to the surface warming and to the increase in the HW durations. In addition, as a response to the decrease in precipitation, evapotranspiration is reduced, contributing to a surface warming.

Different mechanisms, which have been addressed in previous studies, could explain the changes in the atmospheric circulation leading to the cloud cover anomalies and the associated responses in $\mathrm{T} 2 \mathrm{~m}, \mathrm{HW}$, and precipitation over the Euro-Mediterranean region. The Z500 anomalies over the Euro-Atlantic region are found to be part of a circumglobal stationary wave in the Northern Hemisphere, which is more excited during a positive phase of the AMV. Here we argue that the atmospheric circulation anomalies over the North Atlantic and $a$ fortiori over the Northern Hemisphere may be the result from numerous nonexclusive sources, which in turn can be classified into extratropical and tropical sources.

An extratropical warming over the North Atlantic SST during an AMV+ phase could enhance diabatic heating over the midlatitudes inducing a barotropic response over the Atlantic Ocean and Europe. The midlatitude circulation could also be modulated by a warmer than normal tropical Atlantic that may (i) enhance the diabatic heating causing an anomalous wave activity in the upper troposphere over the Euro-Atlantic region and/or (ii) trigger a direct meridional atmospheric cell between the tropics and the Mediterranean basin. Although not addressed in this study, remote effects of AMV on the adjacent oceanic basins (Ruprich-Robert et al. 2017) may also impact the geopotential response via the tropical Pacific through divergence anomalies (O'Reilly et al. 2018) and the Indian Ocean and the Asian monsoon through the eastward propagation of Rossby waves (Rodwell and Hoskins 2001; Cherchi et al. 2014), but a deeper analysis goes beyond the scope of the present paper. Identifying the relevant mechanisms, assessing their respective contribution in each model, and quantifying their sensitivity to the amplitude of the AMV constitute appealing perspectives within the DCPP-C initiative and its multimodel framework, for which several modeling groups have conducted the standard idealized experiments (1xAMV).

A linear relationship between the amplitude of the AMV and the HW/T2m response is found in both models, with a stronger AMV/HW relation in EC-Earth3P due to intrinsic model differences between the two models. One caveat must be raised regarding the interpretation of this linear relationship. Since the restoring coefficient is fixed, the SST restoring tends to be more efficient in the tropics than in the extratropics due to the different mixed layer depths (MLD) between these two regions. SSTs are better constrained in the tropics where the ocean is more stratified than in the extratropics where the mixed layer is thicker. Therefore, more weight may be given to the tropics than the extratropics, potentially leading to (i) an underestimation of the mechanisms of teleconnection from this region, (ii) a different $\mathrm{HW}$ response over Europe, and (iii) a breaking of the linear relation between SST and HW. As done by Ortega et al. (2017), additional experiments in which the restoring coefficient evolves as a function of the MLD have been computed with CNRM-CM5 and EC-Earth3P. Preliminary results indicate that the responses are unchanged.

A last interesting perspective would also be to evaluate the sensitivity of the response to warmer mean background states. We found that this feature has little influence in CNRM-CM5, but there is no guarantee that for a considerably warmer climate, typically characteristic of the mid- to late-twenty-first century, the level of teleconnectivity remains the same given the future abrupt climate changes that could occur depending on anthropogenic emission scenarios. This would provide an estimate of the risks associated with HW few decades ahead.

Acknowledgments. This work was supported by a grant from Electricité de France (EDF), by the French National Research Agency (ANR) in the framework of the MORDICUS project (Grant Agreement ANR-13-SENV-731 0002), and by the European Union's Horizon 2020 Research and Innovation Programme in the framework (i) of the PRIMAVERA project (Grant Agreement 641727) and (ii) of the Marie Skłodowska-Curie grant INADEC (Grant Agreement 800154). The figures were produced with the NCAR Command Language Software (http://dx.doi.org/10.5065/ D6WD3XH5). The authors are grateful to Marie-Pierre Moine, Laure Coquart, and Isabelle d'Ast for technical help to run the CNRM-CM5 model, and to the three anonymous reviewers who provided helpful comments on earlier drafts of the manuscript.

\section{REFERENCES}

Alexander, L., 2011: Extreme heat rooted in dry soils. Nat. Geosci., 4, 12-13, https://doi.org/10.1038/ngeo1045.

_- P. Uotila, and N. Nicholls, 2009: Influence of sea surface temperature variability on global temperature and precipitation extremes. J. Geophys. Res., 114, D18116, https://doi.org/ 10.1029/2009JD012301.

Balsamo, G., A. Beljaars, K. Scipal, P. Viterbo, B. van den Hurk, M. Hirschi, and A. K. Betts, 2009: A revised hydrology for the ECMWF model: Verification from field site to terrestrial water storage and impact in the Integrated Forecast System. J. Hydrometeor., 10, 623-643, https://doi.org/10.1175/2008JHM1068.1.

Bengtsson, L., K. I. Hodges, and E. Roeckner, 2006: Storm tracks and climate change. J. Climate, 19, 3518-3543, https://doi.org/ 10.1175/JCLI3815.1.

Bladé, I., B. Liebmann, D. Fortuny, and G. J. van Oldenborgh, 2012: Observed and simulated impacts of the summer NAO in Europe: Implications for projected drying in the Mediterranean region. Climate Dyn., 39, 709-727, https://doi.org/10.1007/s00382-0111195-x.

Boer, G. J., and Coauthors, 2016: The Decadal Climate Prediction Project (DCPP) contribution to CMIP6. Geosci. Model Dev., 9, 3751-3777, https://doi.org/10.5194/gmd-9-3751-2016.

Cassou, C., L. Terray, and A. S. Phillips, 2005: Tropical Atlantic influence on European heat waves. J. Climate, 18, 2805-2811, https://doi.org/10.1175/JCLI3506.1.

Cherchi, A., H. Annamalai, S. Masina, and A. Navarra, 2014: South Asian summer monsoon and the Eastern Mediterranean climate: The monsoon-desert mechanism in CMIP5 simulations. J. Climate, 27, 6877-6903, https://doi.org/10.1175/JCLI-D-13-00530.1. 
Ciais, P., and Coauthors, 2005: Europe-wide reduction in primary productivity caused by the heat and drought in 2003. Nature, 437, 529-533, https://doi.org/10.1038/nature03972.

Dee, D. P., and Coauthors, 2011: The ERA-Interim reanalysis: Configuration and performance of the data assimilation system. Quart. J. Roy. Meteor. Soc., 137, 553-597, https://doi.org/ 10.1002/qj.828.

Déqué, M., C. Dreveton, A. Braun, and D. Cariolle, 1994: The ARPEGE/IFS atmosphere model: A contribution to the French community climate modelling. Climate Dyn., 10, 249266, https://doi.org/10.1007/BF00208992.

Diffenbaugh, N. S., J. S. Pal, F. Giorgi, and X. Gao, 2007: Heat stress intensification in the Mediterranean climate change hotspot. Geophys. Res. Lett., 34, L11706, https://doi.org/ 10.1029/2007GL030000.

Doblas-Reyes, F. J., and Coauthors, 2013: Initialized near-term regional climate change prediction. Nat. Commun., 4, 1715, https://doi.org/10.1038/ncomms2704.

Dole, R., and Coauthors, 2011: Was there a basis for anticipating the 2010 Russian heat wave? Geophys. Res. Lett., 38, L06702, https://doi.org/10.1029/2010GL046582.

Dong, B., R. T. Sutton, T. Woollings, and K. Hodges, 2013: Variability of the North Atlantic summer storm track: Mechanisms and impacts on European climate. Environ. Res. Lett., 8, 034037, https:// doi.org/10.1088/1748-9326/8/3/034037.

Eyring, V., S. Bony, G. A. Meehl, C. A. Senior, B. Stevens, R. J. Stouffer, and K. E. Taylor, 2016: Overview of the Coupled Model Intercomparison Project Phase 6 (CMIP6) experimental design and organization. Geosci. Model Dev., 9, 19371958, https://doi.org/10.5194/gmd-9-1937-2016.

Gaetani, M., B. Pohl, H. Douville, and B. Fontaine, 2011: West African Monsoon influence on the summer Euro-Atlantic circulation. Geophys. Res. Lett., 38, L09705, https://doi.org/ 10.1029/2011GL047150.

García-Serrano, J., F. J. Doblas-Reyes, and C. S. Coelho, 2012: Understanding Atlantic multi-decadal variability prediction skill. Geophys. Res. Lett., 39, L18708, https://doi.org/10.1029/ 2012GL053283.

Ghosh, R., W. A. Müller, J. Baehr, and J. Bader, 2017: Impact of observed North Atlantic multidecadal variations to European summer climate: A linear baroclinic response to surface heating. Climate Dyn., 48, 3547-3563, https://doi.org/10.1007/ s00382-016-3283-4.

— — _ A. Eichhorn, J. Baehr, and J. Bader, 2019: Atmospheric pathway between Atlantic multidecadal variability and European summer temperature in the atmospheric general circulation model ECHAM6. Climate Dyn., 53, 209-224, https://doi.org/ 10.1007/s00382-018-4578-4.

Giorgi, F., 2006: Climate change hot-spots. Geophys. Res. Lett., 33, L08707, https://doi.org/10.1029/2006GL025734.

Gulev, S. K., M. Latif, N. Keenlyside, W. Park, and K. P. Koltermann, 2013: North Atlantic Ocean control on surface heat flux on multidecadal timescales. Nature, 499, 464-467, https://doi.org/10.1038/nature12268.

Guo, Y., and Coauthors, 2017: Heat wave and mortality: A multicountry, multicommunity study. Environ. Health Perspect., 125, 087006, https://doi.org/10.1289/EHP1026.

Haarsma, R., and Coauthors, 2020: HighResMIP versions of ECEarth: EC-Earth3P and EC-Earth3P-HR-Description, model computational performance and basic validation. Geosci. Model Dev., 13, 3507-3527, https://doi.org/10.5194/gmd-13-3507-2020.

Haney, R. L., 1971: Surface thermal boundary condition for ocean circulation models. J. Phys. Oceanogr., 1, 241-248, https://
doi.org/10.1175/1520-0485(1971)001<0241:STBCFO >2.0. $\mathrm{CO} ; 2$.

Hanlon, H. M., G. C. Hegerl, S. F. B. Tett, and D. M. Smith, 2013: Can a decadal forecasting system predict temperature extreme indices? J. Climate, 26, 3728-3744, https://doi.org/10.1175/ JCLI-D-12-00512.1.

Hansen, J., M. Sato, and R. Ruedy, 2012: Perception of climate change. Proc. Natl. Acad. Sci. USA, 109, E2415-E2423, https:// doi.org/10.1073/pnas.1205276109.

Harris, I., T. J. Osborn, P. Jones, and D. Lister, 2020: Version 4 of the CRU TS monthly high-resolution gridded multivariate climate dataset. Sci. Data, 7, 109, https://doi.org/10.1038/ s41597-020-0453-3.

Huang, B., and Coauthors, 2015: Extended Reconstructed Sea Surface Temperature version 4 (ERSST.v4). Part I: Upgrades and intercomparisons. J. Climate, 28, 911-930, https://doi.org/ 10.1175/JCLI-D-14-00006.1.

Khodayar, S., A. Sehlinger, H. Feldmann, and C. Kottmeier, 2015: Sensitivity of soil moisture initialization for decadal predictions under different regional climatic conditions in Europe. Int. J. Climatol., 35, 1899-1915, https://doi.org/10.1002/joc.4096.

Knight, J. R., R. J. Allan, C. K. Folland, M. Vellinga, and M. E. Mann, 2005: A signature of persistent natural thermohaline circulation cycles in observed climate. Geophys. Res. Lett., 32, L20708, https://doi.org/10.1029/2005GL024233.

Lau, N.-C., and M. J. Nath, 2012: A model study of heat waves over North America: Meteorological aspects and projections for the twenty-first century. J. Climate, 25, 4761-4784, https:// doi.org/10.1175/JCLI-D-11-00575.1.

Lin, J.-S., B. Wu, and T.-J. Zhou, 2016: Is the interdecadal circumglobal teleconnection pattern excited by the Atlantic multidecadal oscillation? Atmos. Oceanic Sci. Lett., 9, 451457, https://doi.org/10.1080/16742834.2016.1233800.

Linderholm, H. W., and C. K. Folland, 2017: Summer North Atlantic Oscillation (SNAO) variability on decadal to palaeoclimate time scales. Past Global Changes Mag., 25, 57-60, https://doi.org/10.22498/pages.25.1.57.

Liu, Y., M. G. Donat, H. W. Rust, L. V. Alexander, and M. H. England, 2019: Decadal predictability of temperature and precipitation means and extremes in a perfect-model experiment. Climate Dyn., 53, 3711-3729, https://doi.org/10.1007/s00382-019-04734-z.

Loboda, T., O. Krankina, I. Savin, E. Kurbanov, and J. Hall, 2017: Land management and the impact of the 2010 extreme drought event on the agricultural and ecological systems of European Russia. Land-Cover and Land-Use Changes in Eastern Europe after the Collapse of the Soviet Union in 1991, G. Gutman and V. Radeloff, Eds., Springer, 173-192.

Madec, G., 2008: NEMO ocean engine. Note du Pôle de modélisation 27, Institut Pierre-Simon Laplace, 193 pp.

Mariotti, A., and A. Dell'Aquila, 2012: Decadal climate variability in the Mediterranean region: Roles of large-scale forcings and regional processes. Climate Dyn., 38, 1129-1145, https:// doi.org/10.1007/s00382-011-1056-7.

Martin, E. R., and C. D. Thorncroft, 2014: The impact of the AMO on the West African monsoon annual cycle. Quart. J. Roy. Meteor. Soc., 140, 31-46, https://doi.org/10.1002/qj.2107.

Meehl, G. A., and C. Tebaldi, 2004: More intense, more frequent, and longer lasting heat waves in the 21 st century. Science, $\mathbf{3 0 5}$, 994-997, https://doi.org/10.1126/science.1098704.

Noilhan, J., and S. Planton, 1989: A simple parameterization of land surface processes for meteorological models. Mon. Wea. Rev., 117, 536-549, https://doi.org/10.1175/1520-0493(1989) $117<0536$ :ASPOLS $>2.0$. CO 2 . 
O'Reilly, C. H., T. Woollings, and L. Zanna, 2017: The dynamical influence of the Atlantic multidecadal oscillation on continental climate. J. Climate, 30, 7213-7230, https://doi.org/ 10.1175/JCLI-D-16-0345.1.

$-, \ldots, \ldots$, and A. Weisheimer, 2018: The impact of tropical precipitation on summertime Euro-Atlantic circulation via a circumglobal wave train. J. Climate, 31, 6481-6504, https:// doi.org/10.1175/JCLI-D-17-0451.1.

Ortega, P., E. Guilyardi, D. Swingedouw, J. Mignot, and S. Nguyen, 2017: Reconstructing extreme AMOC events through nudging of the ocean surface: A perfect model approach. Climate Dyn., 49, 3425-3441, https://doi.org/10.1007/s00382-017-3521-4.

Oudar, T., E. Sanchez-Gomez, F. Chauvin, J. Cattiaux, L. Terray, and C. Cassou, 2017: Respective roles of direct GHG radiative forcing and induced Arctic sea ice loss on the Northern Hemisphere atmospheric circulation. Climate Dyn., 49, 3693 3713, https://doi.org/10.1007/s00382-017-3541-0.

Qasmi, S., C. Cassou, and J. Boé, 2017: Teleconnection between Atlantic multidecadal variability and European temperature: Diversity and evaluation of the Coupled Model Intercomparison Project phase 5 models. Geophys. Res. Lett., 44, 11140-11149, https://doi.org/10.1002/2017GL074886.

$\longrightarrow, \ldots$, and -2020 : Teleconnection processes linking the intensity of the Atlantic multidecadal variability to the climate impacts over Europe in boreal winter. J. Climate, 33, 26812700, https://doi.org/10.1175/JCLI-D-19-0428.1.

Robine, J.-M., S. L. K. Cheung, S. Le Roy, H. Van Oyen, C. Griffiths, J.-P. Michel, and F. R. Herrmann, 2008: Death toll exceeded 70,000 in Europe during the summer of 2003. C. R. Biol., 331, 171-178, https://doi.org/10.1016/j.crvi.2007.12.001.

Robson, J. I., R. T. Sutton, and D. M. Smith, 2012: Initialized decadal predictions of the rapid warming of the North Atlantic Ocean in the mid 1990s. Geophys. Res. Lett., 39, L19713, https://doi.org/10.1029/2012GL053370.

Rodwell, M. J., and B. J. Hoskins, 2001: Subtropical anticyclones and summer monsoons. J. Climate, 14, 3192-3211, https://doi.org/ 10.1175/1520-0442(2001)014<3192:SAASM>2.0.CO;2.

Ruprich-Robert, Y., and C. Cassou, 2015: Combined influences of seasonal East Atlantic Pattern and North Atlantic Oscillation to excite Atlantic multidecadal variability in a climate model. Climate Dyn., 44, 229-253, https://doi.org/10.1007/s00382-0142176-7.

— , R. Msadek, F. Castruccio, S. Yeager, T. Delworth, and G. Danabasoglu, 2017: Assessing the climate impacts of the observed Atlantic multidecadal variability using the GFDL CM2.1 and NCAR CESM1 global coupled models. J. Climate, 30, 2785-2810, https://doi.org/10.1175/JCLI-D-16-0127.1.

—, T. Delworth, R. Msadek, F. Castruccio, S. Yeager, and G. Danabasoglu, 2018: Impacts of the Atlantic multidecadal variability on North American summer climate and heat waves. J. Climate, 31, 3679-3700, https://doi.org/10.1175/JCLID-17-0270.1.

Sanderson, M., T. Economou, K. Salmon, and S. Jones, 2017: Historical trends and variability in heat waves in the United Kingdom. Atmosphere, 8, 191, https://doi.org/10.3390/atmos8100191.
Schneider, U., A. Becker, P. Finger, A. Meyer-Christoffer, and M. Ziese, 2018: GPCC full data monthly version 2018.0 at $0.5^{\circ}$ : Monthly land-surface precipitation from rain-gauges built on GTS-based and historic data. Global Precipitation Climatology Centre, accessed 8 June 2020, https://doi.org/10.5676/DWD_ GPCC/FD_M_V2018_050.

Seager, R., and M. Ting, 2017: Decadal drought variability over North America: Mechanisms and predictability. Curr. Climate Change Rep., 3, 141-149, https://doi.org/10.1007/s40641-0170062-1.

Slivinski, L. C., and Coauthors, 2019: Towards a more reliable historical reanalysis: Improvements for version 3 of the Twentieth Century Reanalysis system. Quart. J. Roy. Meteor. Soc., 145, 2876-2908, https://doi.org/10.1002/qj.3598.

Sutton, R. T., and D. L. R. Hodson, 2005: Atlantic Ocean forcing of North American and European summer climate. Science, 309, 115-118, https://doi.org/10.1126/science.1109496.

— and - 2007: Climate response to basin-scale warming and cooling of the North Atlantic Ocean. J. Climate, 20, 891-907, https://doi.org/10.1175/JCLI4038.1.

- , and B. Dong, 2012: Atlantic Ocean influence on a shift in European climate in the 1990s. Nat. Geosci., 5, 788-792, https://doi.org/10.1038/ngeo1595.

Ting, M., Y. Kushnir, R. Seager, and C. Li, 2009: Forced and internal twentieth-century SST trends in the North Atlantic. J. Climate, 22, 1469-1481, https://doi.org/10.1175/2008JCLI2561.1.

,-- , and C. Li, 2014: North Atlantic multidecadal SST Oscillation: External forcing versus internal variability. J. Mar. Syst., 133, 27-38, https://doi.org/10.1016/j.jmarsys.2013.07.006.

van Oldenborgh, G. J., F. J. Doblas-Reyes, B. Wouters, and W. Hazeleger, 2012: Decadal prediction skill in a multi-model ensemble. Climate Dyn., 38, 1263-1280, https://doi.org/10.1007/ s00382-012-1313-4.

Voldoire, A., and Coauthors, 2013: The CNRM-CM5.1 global climate model: Description and basic evaluation. Climate Dyn., 40, 2091-2121, https://doi.org/10.1007/s00382-011-1259-y.

Wang, H., B. Wang, F. Huang, Q. Ding, and J.-Y. Lee, 2012: Interdecadal change of the boreal summer circumglobal teleconnection (1958-2010). Geophys. Res. Lett., 39, L12704, https://doi.org/10.1029/2012GL052371.

Yeager, S. G., and Coauthors, 2018: Predicting near-term changes in the Earth system: A large ensemble of initialized decadal prediction simulations using the Community Earth System Model. Bull. Amer. Meteor. Soc., 99, 1867-1886, https:// doi.org/10.1175/BAMS-D-17-0098.1.

Zampieri, M., F. D'Andrea, R. Vautard, P. Ciais, N. de NobletDucoudré, and P. Yiou, 2009: Hot European summers and the role of soil moisture in the propagation of Mediterranean drought. J. Climate, 22, 4747-4758, https://doi.org/10.1175/ 2009JCLI2568.1.

Zhang, R., and T. L. Delworth, 2006: Impact of Atlantic multidecadal oscillations on India/Sahel rainfall and Atlantic hurricanes. Geophys. Res. Lett., 33, L17712, https://doi.org/10.1029/ 2006 GL026267. 
Copyright of Journal of Climate is the property of American Meteorological Society and its content may not be copied or emailed to multiple sites or posted to a listserv without the copyright holder's express written permission. However, users may print, download, or email articles for individual use. 